\title{
EVALUATION OF DU PONT COPPER-COMPATIBLE RESISTOR SYSTEM
}

\author{
M.V. COLEMAN and G.E. GURNETT \\ Standard Telecommunication Laboratories Limited, London Road, Harlow, Essex, U.K.
}

(Received in final form October 26, 1981)

Four nitrogen-fireable resistor inks with resistivities from $20 \Omega / \square$ to $10 \mathrm{k} \Omega / \square$ were examined and found to be based upon lanthanum hexaboride. The firing conditions, especially the peak temperature value and oxygen content, considerably affected both the fired resistance value and the shape and slope of the TCR curve. Titanium monoxide was present in the low value resistivity inks and had the effects of modifying the TCR curves in the room temperature region. The stability of the resistor system, especially after ageing at elevated temperatures, was found to be comparable with that of the 'Birox' 1400 resistor system. The resistance generally increased in value and the rate of change of resistance could be approximated to a square root of time law consistent with a diffusion mechanism.

\section{INTRODUCTION}

For the past few years thick film copper conductors have been available which have high conductivity and are easily solderable as well as being solder leach resistant. ${ }^{1}$ With the exception of microwave properties, these conductors could provide low cost replacements for noble metal conductors in hybrid circuits. The limitation of using copper conductors in thick film hybrids has been the lack of a compatible nitrogen-fireable resistor system and, to a lesser extent, a compatible dielectric material.

$\mathrm{Du}$ Pont has recently released a nitrogen-fireable resistor system based upon an experimental system which has been available with a limited range of resistivities from $20 \Omega / \square$ to $10 \mathrm{k} \Omega / \square$. This system is compatible with copper conductors and the composition is based upon lanthanum hexaboride as the conducting phase. This material has been referenced in the literature as an electron emitter and also has properties suitable for thick film resistors. ${ }^{2}$

\section{COMPOSITION AND STRUCTURE}

The four resistivity inks were $20 \Omega / \square(E 17767-42), 100 \Omega / \square$ (E17767-43), $1 \mathrm{k} \Omega / \square$ (E17767-50) and $10 \mathrm{k} \Omega / \square(\mathrm{E} 17767-49)$ and two copper conductors DP 9922 and DP 9923. The composition of the four resistor inks was determined by atomic adsorption spectroscopy and the major components identified, Table 1.

A number of minority constituents were also identified with amounts less than $1 \%$ including, $\mathrm{MgO}$ and $\mathrm{MnO}$. The glass composition was the same for all four inks and was approximately, $\mathrm{B}_{2} \mathrm{O}_{3}(35 \%), \mathrm{SiO}_{2}(34 \%), \mathrm{Al}_{2} \mathrm{O}_{3}(21 \%), \mathrm{CaO}(10 \%)$ confirming the broad formulation given in a Du Pont patent application. ${ }^{3}$ The conducting phase was confirmed to be $\mathrm{LaB}_{6}$ by X-ray diffraction, but no other crystalline phase was identified.

Individual particles of the dried inks were analysed on the SEM using non-dispersive $\mathrm{X}$-ray analysis and it was verified that three separate phases existed, lanthanum hexaboride, a glass containing calcium, aluminium and silicon and titanium rich particles. The titanium rich phase was only detected on the SEM in the two low value resistivity 
TABLE 1

Composition of resistor inks, weight percent.

\begin{tabular}{lrrrr}
\hline & $20 \Omega / \square$ & $100 \Omega / \square$ & $1 \mathrm{k} \Omega / \square$ & $10 \mathrm{k} \Omega \square$ \\
\hline $\mathrm{LaB}_{6}$ & 39.2 & 30.9 & 29.0 & 19.2 \\
$\mathrm{TiO}$ & 4.0 & 3.4 & 0.4 & 0.4 \\
$\mathrm{~B}_{2} \mathrm{O}_{3}$ & 14.8 & 19.5 & 22.4 & 24.4 \\
$\mathrm{SiO}_{2}$ & 13.6 & 18.5 & 23.2 & 23.2 \\
$\mathrm{Al}_{2} \mathrm{O}_{3}$ & 8.3 & 11.1 & 14.4 & 14.8 \\
$\mathrm{CaO}$ & 4.0 & 4.8 & 7.8 & 6.8 \\
\hline
\end{tabular}

inks. It was subsequently confirmed by a Du Pont patent application, ${ }^{3}$ that titanium monoxide was used as a temperature coefficient of resistance (TCR) modifier.

\section{EFFECT OF PEAK FIRING TEMPERATURE}

\section{Effect on resistance value.}

Each resistivity ink, terminated with DP 9922 copper conductors, was printed on a test pattern which included five $1 \mathrm{~mm}$ width resistors with increasing lengths from $1 \mathrm{~mm}$ to $5 \mathrm{~mm}$. Two substrates for each resisitivity were fired at peak temperatures of $850^{\circ} \mathrm{C}$, $860^{\circ} \mathrm{C}, 880^{\circ} \mathrm{C}, 900^{\circ} \mathrm{C}, 920^{\circ} \mathrm{C}, 940^{\circ} \mathrm{C}$ and $950^{\circ} \mathrm{C}$ under a blanket of nitrogen such that there was less than $10 \mathrm{ppm}$ oxygen throughout the heated length of the furnace. Curves of $\rho l / l$, were plotted, where $\rho$ is the resistivity in $\Omega / \square$ and $l$ is the resistor length in $\mathrm{mm}$, for the five different aspect ratio resistors. The gradient is the bulk resistivity in $\Omega / \square$ and the intercept with the abscissa, $\Delta l$, is a measure of the length of the interaction region between the conductor and resistor.

The average resistor thickness was determined, using Talysurf equipment, for each of the inks and was found to be $15.5 \mu \mathrm{m}$ for the $20 \Omega / \square$ ink, $13 \mu \mathrm{m}$ for the $100 \Omega / \square$, $13 \mu \mathrm{m}$ for the $1 \mathrm{k} \Omega / \square$, and $11.5 \mu \mathrm{m}$ for the $10 \mathrm{k} \Omega / \square$. The resistivity, $\rho_{\mathrm{b}}$ was calculated in $\Omega \mathrm{cm}$ for the four resistivity inks and is listed in Table II. The nominal bulk resistivity for each of the inks should be $31 \mathrm{~m} \Omega \mathrm{cm}$ for the $20 \Omega / \square, 130 \mathrm{~m} \Omega \mathrm{cm}$ for the $100 \Omega / \square$, $1.3 \Omega \mathrm{cm}$ for the $1 \mathrm{k} \Omega / \square$, and $11.5 \Omega \mathrm{cm}$ for the $10 \mathrm{k} \Omega / \square$.

The bulk resistivity value for the $20 \Omega / \square$ was fairly constant when fired above $860^{\circ} \mathrm{C}$ but was higher at the lower temperatures. The $100 \Omega / \square$ ink had a minimum around $880^{\circ} \mathrm{C}$ and the resistance value at $950^{\circ} \mathrm{C}$ was nearly doubled. The $1 \mathrm{k} \Omega / \square$ and $10 \mathrm{k} \Omega / \square$ resistors were extremely sensitive to firing temperature and the higher the temperature, the lower the resistance value. Below $880^{\circ} \mathrm{C}$, the resistance values were so high as to suggest that

TABLE II

Bulk resistivity, $\rho_{\mathrm{b}}$ in $\Omega \mathrm{cm}$ and interaction length, $\Delta l$ in $\mathrm{mm}$ of four resistivity inks.

\begin{tabular}{lllllrrrr}
\hline \multirow{2}{*}{$\begin{array}{c}\text { Peak } \\
\text { Temp }^{\circ} \mathrm{C}\end{array}$} & \multicolumn{2}{c}{$20 \Omega / \square$} & \multicolumn{2}{c}{$100 \Omega / \square$} & \multicolumn{2}{c}{$1 \mathrm{k} \Omega / \square$} & \multicolumn{2}{c}{$10 \mathrm{k} \Omega / \square$} \\
\hline 850 & 67.4 & 0.19 & 191.8 & 0.24 & 9.23 & 0.22 & 122.0 & 0.38 \\
860 & 65.1 & 0.18 & 211.3 & 0.20 & 5.66 & 0.00 & 72.5 & 0.18 \\
880 & 41.9 & 0.18 & 159.3 & 0.26 & 1.99 & 0.16 & 15.3 & 0.28 \\
900 & 38.8 & 0.17 & 204.8 & 0.18 & 1.27 & 0.14 & 9.2 & 0.26 \\
920 & 38.8 & 0.17 & 221.0 & 0.22 & 1.21 & 0.24 & 7.2 & 0.20 \\
940 & 38.8 & 0.17 & 269.8 & 0.22 & 0.88 & 0.12 & 4.4 & 0.14 \\
950 & 41.4 & 0.16 & 286.0 & 1.24 & 0.88 & 0.12 & 4.0 & 0.10 \\
\hline
\end{tabular}


TABLE III

Bulk resistivity, $\rho_{\mathrm{b}}$ in $\Omega \mathrm{cm}$.

\begin{tabular}{llllc}
\hline $\begin{array}{c}\text { Peak } \\
\text { Temp }^{\circ} \mathrm{C}\end{array}$ & \multicolumn{1}{c}{$20 \Omega / \square$} & \multicolumn{1}{c}{$100 \Omega / \square$} & $1 \mathrm{k} \Omega / \mathrm{a}$ & $10 \mathrm{k} \Omega / \mathrm{a}$ \\
\hline 870 & $43.3 \times 10^{-3}$ & $176.2 \times 10^{-3}$ & 3.17 & 23.68 \\
880 & 39.6 & 188.0 & 2.17 & 16.88 \\
890 & 40.9 & 188.4 & 1.98 & 11.76 \\
900 & 44.2 & 259.8 & 1.33 & 8.58 \\
910 & 39.2 & 256.0 & 1.22 & 6.53 \\
$880 / \mathrm{O}_{2}$ & 72.4 & 341.8 & 5.20 & 83.20 \\
$890 / \mathrm{O}_{2}$ & 73.0 & 400.0 & 5.20 & 38.40 \\
$900 / \mathrm{O}_{2}$ & 59.6 & 480.0 & 3.35 & 18.77 \\
\hline
\end{tabular}

the required resistor chemistry had not been fully achieved. The interaction length was around $0.1 \mathrm{~mm}$ at each end of the resistor except for the $10 \mathrm{k} \Omega / \square$ sample fired at $850^{\circ} \mathrm{C}$, when it was approximately double this value. A second set of the four resistivity inks was printed on a similar test pattern with $1 \mathrm{~mm}$ resistors from $1 \mathrm{~mm}$ length to $10 \mathrm{~mm}$ length and fired through profiles between $870^{\circ} \mathrm{C}$ and $910^{\circ} \mathrm{C}$. The printed thicknesses were about $50 \%$ greater but the bulk resistivity values were consistent with those obtained previously, Table III. Part of the batch was fired through the furnace at $880^{\circ} \mathrm{C}, 890^{\circ} \mathrm{C}$ and $900^{\circ} \mathrm{C}$ with a controlled amount of oxygen bled into the firing zone, equivalent to approximately $170 \mathrm{ppm}$ at the peak temperature, Table III. The effect was to considerably in crease the resistance values.

\section{Effect on TCR.}

A Ransco (Model SD60) oven capable of controlling temperatures between $-77^{\circ} \mathrm{C}$ and $250^{\circ} \mathrm{C}$ was modified to allow programmed cycling between $-50^{\circ} \mathrm{C}$ and $+160^{\circ} \mathrm{C}$. A substrate for each resistivity ink fired at a peak temperature of $900^{\circ} \mathrm{C}$ was chosen and the TCR curves determined, Figures $1 \mathrm{a}-\mathrm{d}$. The TCR curves expected for thick film resistors have a positive TCR above about $50^{\circ} \mathrm{C}$, consistent with metallic-type conduction, and a negative TCR below $0^{\circ} \mathrm{C}$, consistent with semiconductor type conduction. A minimum in resistance is therefore obtained near room temperature. With the exception of the $10 \mathrm{k} \Omega / \square$ ink, the nitrogen-fireable resistors fired at $900^{\circ} \mathrm{C}$ had TCR curves unlike those previously found with air-firing ruthenium dioxide based systems. The $1 \mathrm{k} \Omega / \square$ ink had an almost linear positive TCR of about $110 \mathrm{ppm} /{ }^{\circ} \mathrm{C}$ equivalent to a temperature coefficient, $\alpha=1.1 \times 10^{-4}$ compared with bulk lanthanum hexaboride, $\alpha_{\mathrm{LaB}_{6}}=2.6 \times 10^{-3}$. The curves for $20 \Omega / \square$ and $100 \Omega / \square$ show a positive TCR except in the temperature range from about $40^{\circ} \mathrm{C}$ to $100^{\circ} \mathrm{C}$ where there is a negative TCR. This exaggerated point of inflexion serves to reduce the TCR in the normal operation range and may be an effect introduced by titanium monoxide. The TCR curves of the $1 \mathrm{k} \Omega / \square$ resistors fired at peak temperatures from $850^{\circ} \mathrm{C}$ to $950^{\circ} \mathrm{C}$, were determined (Figure 2a.) As the peak firing temperature is reduced, the resistance at room temperature increases and the slope of the TCR becomes less positive and at $850^{\circ} \mathrm{C}$ is negative. Further resistance measurements were taken down to liquid nitrogen temperature, $-196^{\circ} \mathrm{C}$, and in each case, except the resistors fired at $850^{\circ} \mathrm{C}$, the resistance eventually reduced to a minimum value and the TCR became negative, (Figure 2a.) The resistors fired at a peak temperature of $850^{\circ} \mathrm{C}$ had negative TCR curves and there was no evidence of a resistance minimum even when tested up to $250^{\circ} \mathrm{C}$. 

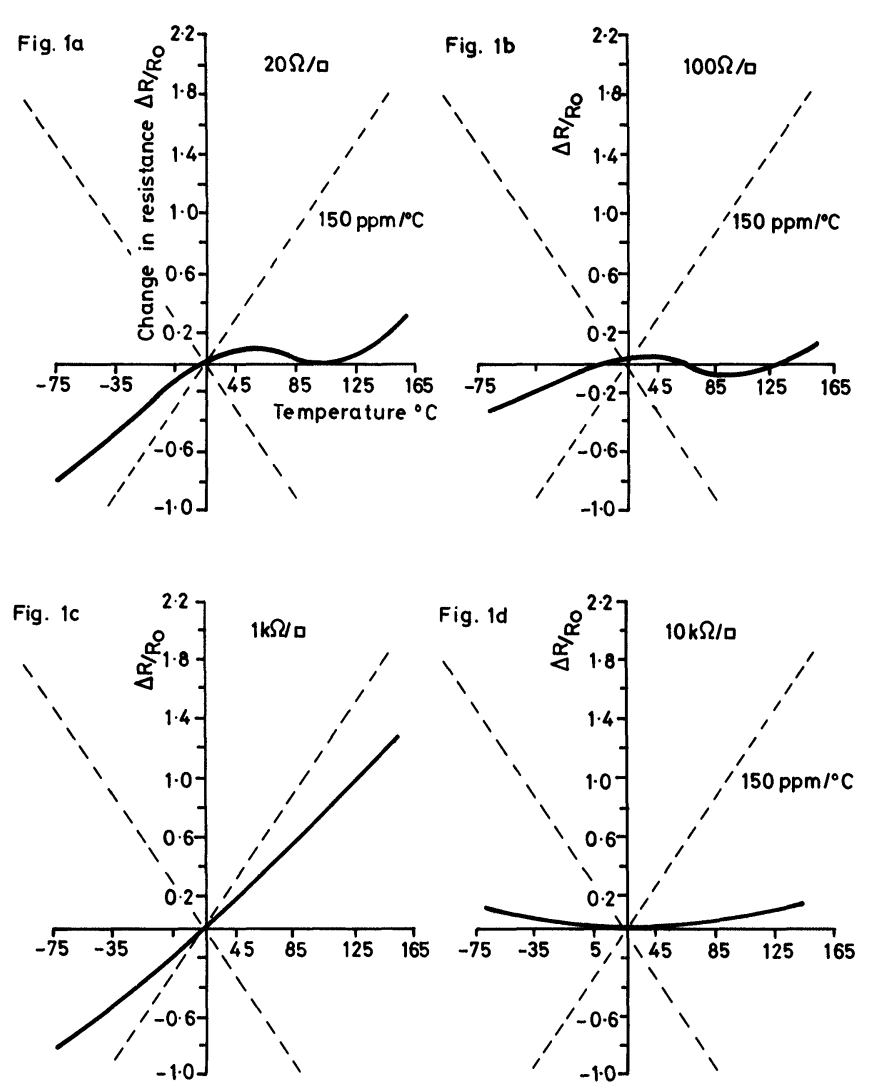

FIGURE 1 Temperature coefficient of resistance of $4 \mathrm{~mm} \times 4 \mathrm{~mm}$ resistors fired at $900^{\circ} \mathrm{C}$.

A similar analysis was made of the $20 \Omega / \square$ resistors, (Figure 2b.) At the highest firing temperatures the TCR curves were positive with no evidence of a minimum or a point of inflexion down to liquid nitrogen temperatures. The resistors fired at lower peak temperatures had clearly defined negative TCR behaviour at the low temperatures and positive TCR at high temperatures, and a complex double minimum in resistance value in the normal operational temperature range.

\section{STABILITY}

Eight substrates for each resistivity ink were printed and fired at a peak temperature of $900^{\circ} \mathrm{C}$ with less than $10 \mathrm{ppm}$ oxygen in the firing zones. The resistance values were measured and five substrates aged in air at $200^{\circ} \mathrm{C}$, two in air at $125^{\circ} \mathrm{C}$ and one substrate held at room temperature as a standard. Oxidation of the copper conductors occurred especially for the substrates aged at $200^{\circ} \mathrm{C}$ and care had to be taken to remove the oxide layer before each resistance measurement. The percentage change in resistance from the initial value, $\Delta R / R_{0}$ was plotted on $\log / \log$ graphs, (Figures $3 a-d$.) The changes in resistance followed positive trends with the exception of the $10 \mathrm{k} \Omega / \square$ ink which was negative when aged at $125^{\circ} \mathrm{C}$. The equivalent average changes for the unglazed DP 1400 resistor series are plotted for comparison and the stability especially at the lower temp- 


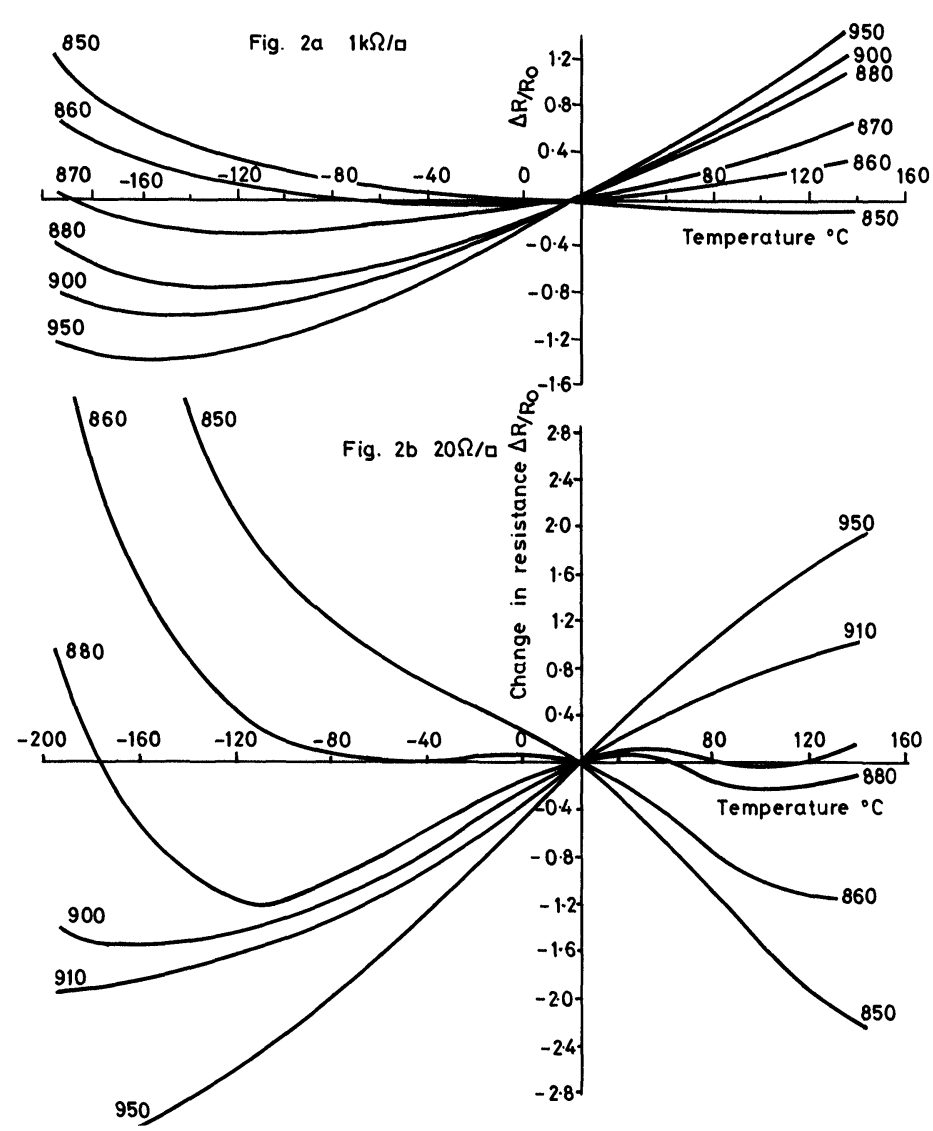

FIGURE 2 TCR curves of $1 \mathrm{k} \Omega / \square$ and $20 \Omega / \square$ resistors for various peak firing temperatures.

eratures compares favourably with this series. The rate of change of resistance for the $20 \Omega / \square$ and $100 \Omega / \square$ resistors aged at $200^{\circ} \mathrm{C}$ and $125^{\circ} \mathrm{C}$ fitted reasonably well to a square root of time law consistent with a diffusion process. This is a faster rate of change at $125^{\circ} \mathrm{C}$ than for the DP 1400 'Birox' series and, if continued, would lead to greater increases at longer times (ie a crossover will occur probably after between $10^{4}$ and $10^{5}$ hours). The rate of change for the $1 \mathrm{k} \Omega / \square$ at $200^{\circ} \mathrm{C}$ is greater than $\mathrm{t}^{1 / 2}$ but at $125^{\circ} \mathrm{C}$ is less than $\mathrm{t}^{1 / 3}$, as for the DP 1400 series. The $10 \mathrm{k} \Omega / \square$ results were disappointing in comparison, with sometimes negative changes of over $1 \%$ being found after a few thousand hours at $125^{\circ} \mathrm{C}$.

Substrates for each resistivity ink for each peak firing temperature in both nitrogen and partial oxygen firing conditions, as defined in Table III, were aged in air at $150^{\circ} \mathrm{C}$. The changes in resistance, $\Delta R / R_{0}$ were measured and after 2500 hours, the spread in $\Delta R / R_{0}$ was as shown in Table IV.

With the exception of the two high resistivity inks fired at a peak temperature of $880^{\circ} \mathrm{C}$ in $170 \mathrm{ppm}$ of oxygen, the stabilities were extremely good for all resistors under all conditions. The resistance changes were generally positive although some negative changes were observed and the average rate could be approximated to a $t^{1 / 2}$ law, as before. The average $\Delta R / R_{0}$ for the $10 \mathrm{k} \Omega / \square$ ink was positive and better behaved than observed previously for samples aged at $125^{\circ} \mathrm{C}$ and the resistance change was comparable to that found at $200^{\circ} \mathrm{C}$, (Figure 3d.) 

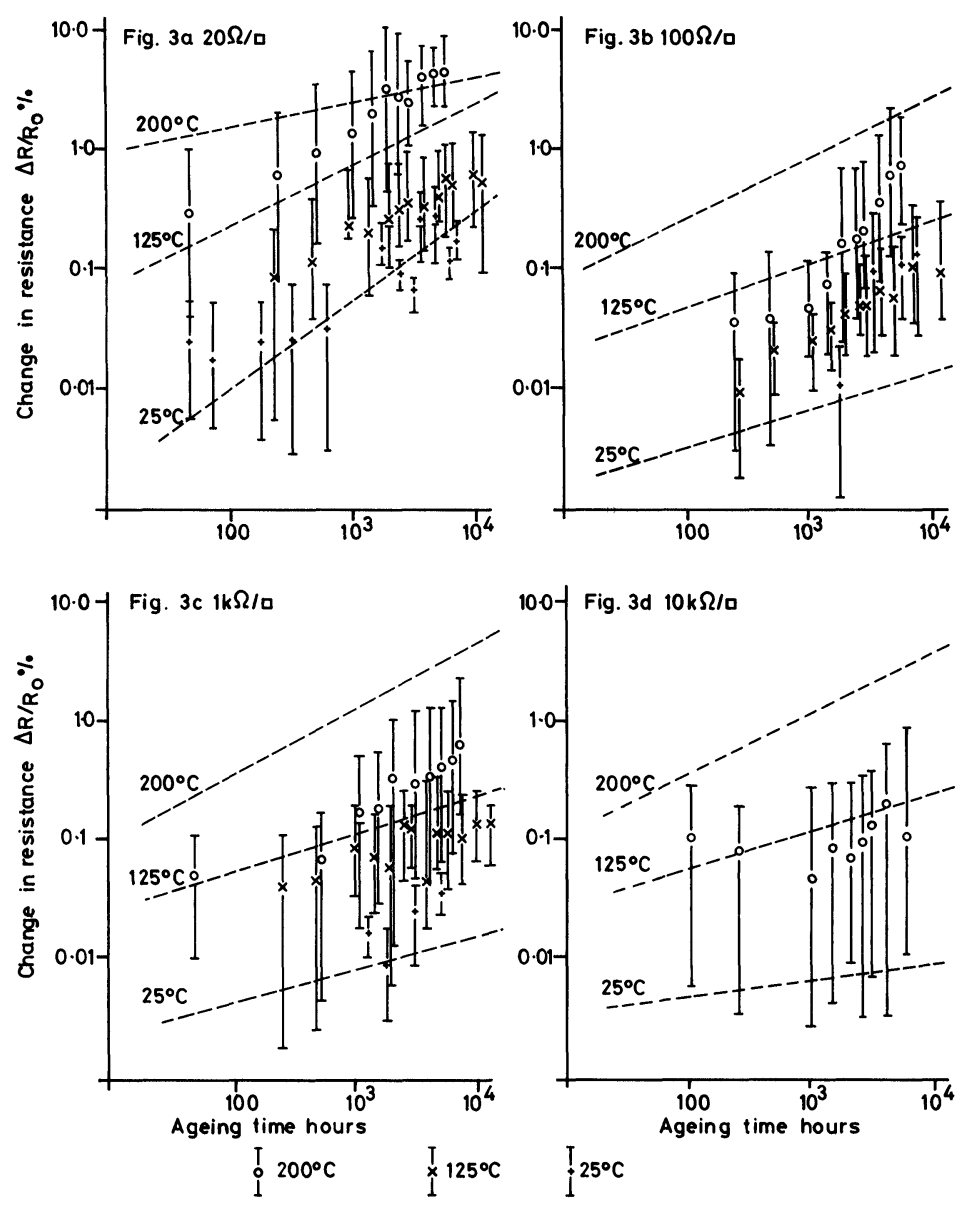

FIGURE 3 Change in resistance with time after thermal ageing.

TÁBLE IV

Spread of percentage change in resistance, $\Delta R / R_{0}$ after 2500 hours at $150^{\circ} \mathrm{C}$

\begin{tabular}{lrlrr}
\hline $\begin{array}{c}\text { Peak } \\
\text { Temp }^{\circ} \mathrm{C}\end{array}$ & $20 \Omega / \square$ & $100 \Omega / \square$ & $1 \mathrm{k} \Omega /$ 口 & $10 \mathrm{k} \Omega /$ 口 \\
\hline 870 & 0.3 to 1.1 & -0.2 to 0.6 & -0.7 to 0.6 & -1.0 to 1.7 \\
880 & 0.4 to 2.4 & -0.2 to 0.4 & -0.7 to 0.7 & -0.1 to 0.6 \\
890 & -0.5 to 1.0 & -0.3 to 0.5 & -1.1 to 0.8 & -0.3 to 0.8 \\
900 & 0.1 to 1.3 & -0.3 to 0.7 & 0.1 to 1.3 & -0.9 to 0.8 \\
910 & 0.2 to 1.3 & -0.5 to 0.5 & -0.9 to 0.5 & -1.1 to 0.9 \\
$880 / \mathrm{O}_{2}$ & -0.9 to 0.2 & -1.2 to 0.2 & 0.0 to 20.0 & -17.0 to 0.9 \\
$890 / \mathrm{O}_{2}$ & -1.3 to 0.0 & -1.2 to 0.2 & -1.0 to 1.6 & -0.8 to 0.9 \\
$900 / \mathrm{O}_{2}$ & -0.3 to 1.1 & -1.1 to 0.5 & -0.8 to 1.2 & -1.0 to 0.7 \\
\hline
\end{tabular}

\section{DISCUSSION}

The experimental nitrogen firing system is well-behaved and stable even when fired at other than the recommended peak temperature. As well as thermal ageing, experiments 
in $85 \%$ relative humidity at $85^{\circ} \mathrm{C}$ and under DC load after laser trimming have given results that are similar to those found for the unglazed DP 1400 'Birox' resistor system. At present, however, no overglaze is available for the nitrogen fireable system, and generally the overglazed DP 1400 system performs much better than when it is unglazed.

The ageing mechanism was consistent with a diffusion process and may be associated with oxygen movement as was the case for air fireable systems. ${ }^{4}$ Whether oxidation of any component within the resistor system occurs was not determined, but on heating the unfired inks to $750^{\circ} \mathrm{C}$ in air for two hours weight gains were found, $11 \%$ for $20 \Omega / \square$, $4 \%$ for $100 \Omega / \square$ and $2.5 \%$ for $1 \mathrm{k} \Omega / \square$. Reference is made in the STC patent to the ability to fire lanthanum hexaboride in air but the resistance values obtained in air are considerably greater than those in nitrogen. This is substantiated by the results of firings in $170 \mathrm{ppm}$ oxygen and suggested that oxidation of lanthanum hexaboride can occur at least at elevated temperatures.

The TCR curves and resistance values are sensitive to firing temperature (and furnace atmosphere) and it is only by the addition of titanium monoxide to the lower resistivity inks that sufficiently low TCR values are obtained in the operational temperature range. The metallic type conduction of the lathanum hexaboride tends to dominate the behaviour of the low resistivity inks but at sufficiently low temperatures a negative TCR consistent with semiconductor behaviour was observed. Titanium monoxide is a narrow band oxide that behaves like a metal, with a room temperature resistivity of about $0.28 \mathrm{~m} \Omega \mathrm{cm}$ and may act as an electron donor with a slight positive TCR over a limited temperature range (the negative TCR of the semiconducting phase must again dominate at higher temperatures before the positive TCR behaviour of the lanthanum hexaboride takes over). The change in slope of the positive TCR curves with firing conditions of the high resistivity inks is difficult to understand but the slope is always considerably less than that for bulk lanthanum hexaboride. It is likely, therefore, that there is interaction between the conducting phase and the glass, as has been suggested for air fireable systems. ${ }^{5}$ Lanthanum hexaboride is well known as a reducing agent and although the glass is specified as non-reducing, some reduction may occur at the lanthanum hexaboride-glass interface, leading to reduced resistance values and more positive TCR. The $10 \mathrm{k} \Omega / \square$ ink has a well defined minimum in the TCR curve and for higher resistivities a negative TCR would be expected. This negative TCR may be large and could explain the difficulties experienced in extending the series to $100 \mathrm{k} \Omega / \square$.

\section{CONCLUSIONS}

A nitrogen-fireable copper compatible resistor system has been successfully produced by Du Pont, albeit limited in range. The processing conditions need careful control but the stability and likely long-life reliability of the resistor system appears to be good. If these inks can be successfully encapsulated, a new generation of low cost thick film materials for hybrid applications should be in production in the next few years.

\section{ACKNOWLEDGEMENTS}

The authors wish to thank Standard Telecommunication Laboratories Limited for permission to publish this paper. Acknowledgement is made to Mr. J. Woolley for the chemical analyses. Special thanks are due to colleagues within STC Components Group UK for their help and support in the investigation. Thanks are also due to $\mathrm{Du}$ Pont for providing samples of their experimental inks before general release. 


\section{REFERENCES}

1. M. Hrovat and G.E. Gurnett, "The Influence of Firing Conditions on the Properties of Some Copper-Based Thick Film Compositions", XV Yugoslav Symposium on Electronic Components and Materials, Ljubljana, p. 217, (1979).

2. W.A. Crossland and C.A. Marr, Electrical Resistor Material, STC British Patent 1282023.

3. P.C. Donohue and S.M. Marcus, Resistor Composition Comprising a Temperature Coefficient of Resistance Modifier for Thick Film Resistors, Du Pont European Patent Application 0008133; P.C. Donohue, Resistor and/or Conductor Composition Comprising a Hexaboride Conductive Material for Thick Film Resistors, Du Pont European Application 0008437.

4. M.V. Coleman, "The Effect of Nitrogen and Nitrogen-Hydrogen Atmospheres on the Stability of Thick Film Resistors", ISHM US Conference p. 255, (1979).

5. T.V. Nordstrom and C.R. Hills, "Microstructural Studies of Thick Film Resistors Using Transmission Electron Microscopy", ISHM US Conference p. 40, (1979). 

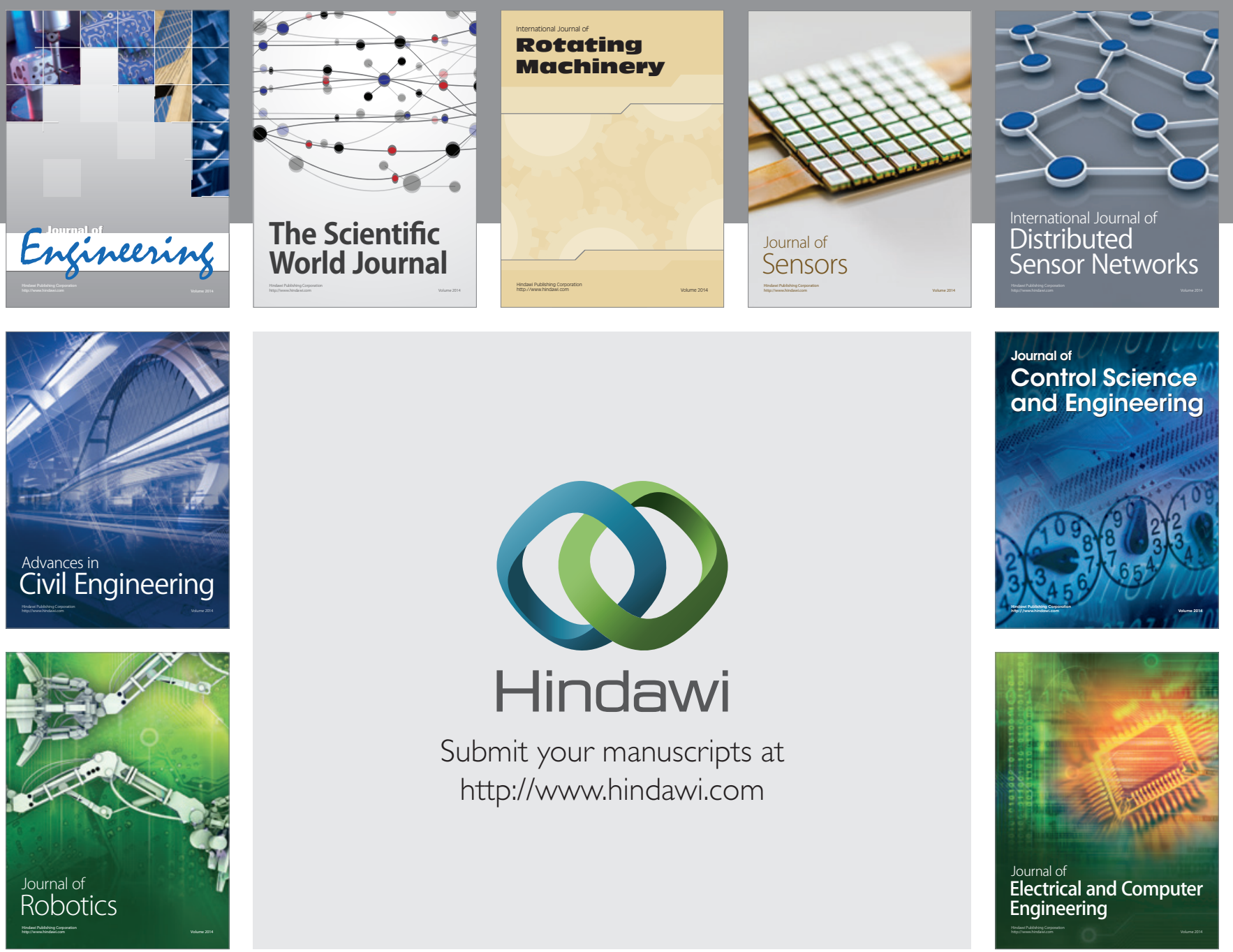

Submit your manuscripts at

http://www.hindawi.com
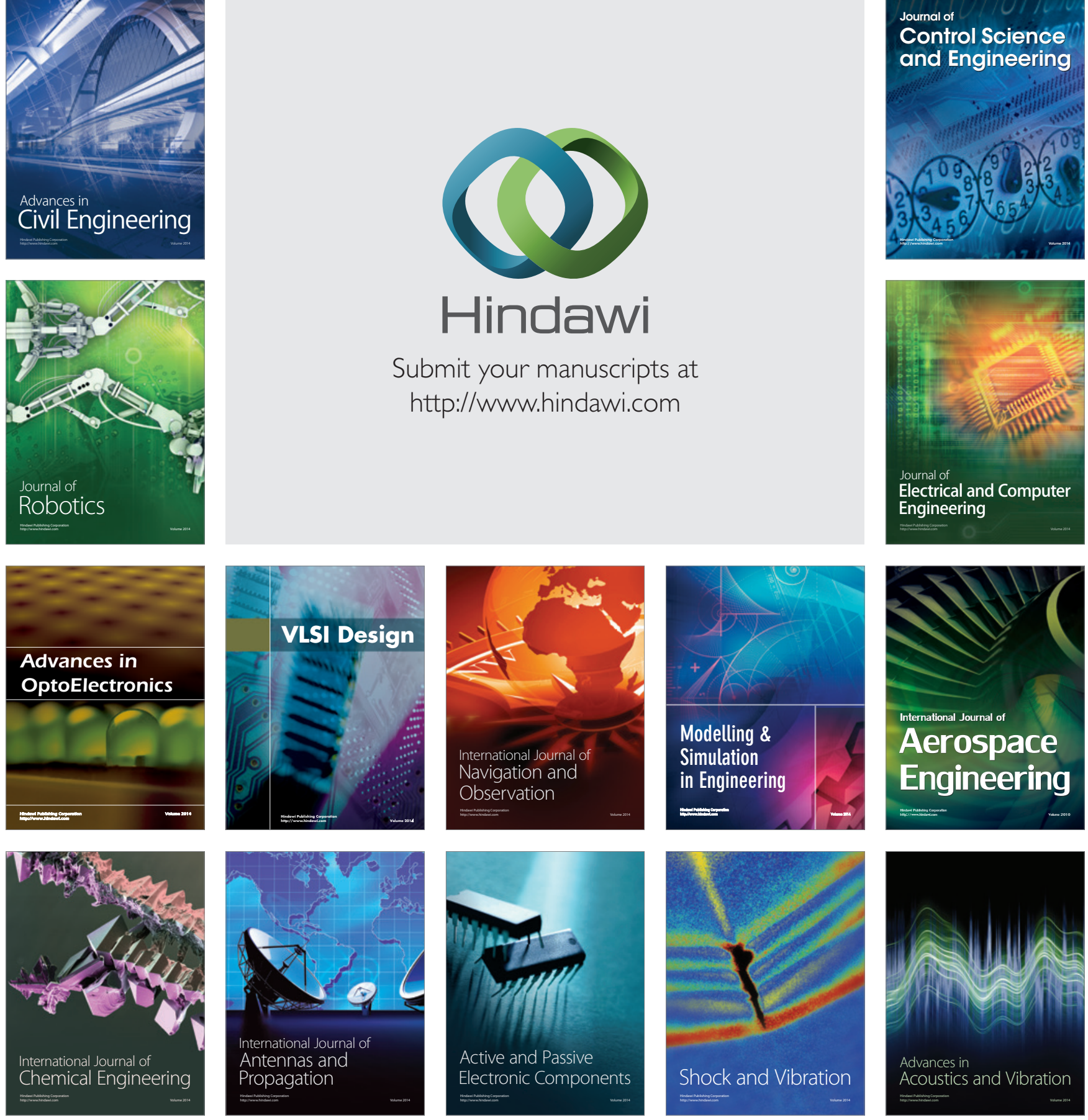